\title{
An Analysis of Affirmative Action in a South African Public Sector Department
}

\author{
H E Brand and S Stoltz
}

Department of Human Resources Management, University of Pretoria

\section{ABSTRACT}

The South African labour market is characterised by a diversity of ethnic and cultural groups. The public sector is experiencing pressure from social, economic, political and legislative circles to make the workplace more representative of the population. This study investigated the affirmative action process in a national public sector department in terms of its employees' perceptions of that process. A questionnaire was developed and used as measuring instrument on a random sample of the department's employee population. Results show that the affirmative action process did influence employees' perceptions of their working life and career, and that the majority of respondents perceived the affirmative action process not to be successful.

JEL J 53

\section{INTRODUCTION}

South Africa's history of so-called state controlled inequity played a major role in causing the main fundamental right of the National Constitution to be equality. De Waal, Currie and Erasmus (1998: 153) mentions in this regard: "...there can be no doubt that the guarantee of equality lies at the very heart of the Constitution. It permeates and defines the very ethos upon which the Constitution is premised". Clause $9(2)$ of the Constitution addresses the issue of affirmative action and clearly indicates that affirmative action does not infringe on a person's fundamental right not to be discriminated against on the basis of race, sex, religion, etc. According to Gerber, Nel and van Dyk (1998), the broad concept of affirmative action can be viewed as an instrument in the process of national reconstruction or even transformation, to eliminate the inequality due to discrimination in the past.

Most countries with a heterogeneous population composition, had to implement affirmative action at some stage in their history to redress inequalities due to unequal opportunities (Skretny, 1996). Affirmative action should be used in the national interest with the aim to support those people in the population who have 
been disadvantaged by discriminatory laws and regulations, enabling them to develop and maintain themselves in society (Luhabe, 1993).

In South Africa, the need for affirmative action originated from problems relating especially to unequal land distribution, as well as unequal economic, socio-economic, and political issues (Wingrove, 1995). Unequal representation of members of different population groups in management positions in the public sector is an important issue that often causes conflict and friction. Affirmative action is seemingly the most acceptable process to redress this situation. This process should be used as a form of redressing on the basis of merit, and should not be seen as a process to seize power. Thus the emphasis should be on correcting and not on discrimination (White Paper on Affirmative Action in the Public Service, Notice 564, 1998). The process should also focus on creating opportunities for those who were discriminated against on the basis of race, sex, religion or language.

Transformation in the South African public sector was inspired by a vision of person-centered or person-driven public administration characterised by the principles of equality, quality, high ethical standards and professionalism (White Paper on the Transformation of the Public Service, Notice 1227, 1995). The objective of affirmative action in the public sector is defined in the following manner in the White Paper on Affirmative Action in the Public Service, Notice 564, 1998: "The goal of affirmative action in the public service is to speed up the creation of a representative and equitable Public Service and to build an environment that supports and enables those who have been historically disadvantaged by unfair discrimination to fulfil their maximum potential within it, so that the Public Service may derive the maximum benefit of their diverse skills and talents to improve service delivery."

Affirmative action can thus be conceptualised as a strategy for achieving employment equity by addressing inequalities in the areas of organisation culture, personnel composition, human resource practices, service provision and by improving the circumstances of groups and individuals in the workplace. These aspects are to be realised through the creation and utilisation of legislation, programmes and activities to remove injustice and discrimination from the workplace (White Paper on Human Resource Management in the Public Sector, Notice 2011, 1997).

\section{THIS STUDY}

In the light of the necessity for and problems related to the implementation of an affirmative action policy in the South African public sector, a prominent, 
national public sector department contracted the authors to do a study of its affirmative action process in terms of its employees' perceptions of this sensitive process, and this is the main objective of this study. The study is also aimed at identifying possible shortcomings of the process and proposing guidelines for more positive and effective affirmative action.

As the study focuses on the department's employee perceptions of the affirmative action process, which involves no comparisons of variables, no hypotheses to be tested were formulated.

\section{Research Method}

The research method followed in this study is discussed under the headings of research strategy, research group, sample, response rate and data analysis.

\section{Research Strategy}

The survey method, to determine the impact of an affirmative action process on the perceptions of employees of the public sector department, was considered to be the appropriate research method for this study. A questionnaire, using a fivepoint Likert scale, was developed and applied to a sample drawn at random from the employees of the department concerned. The questionnaires were distributed together with an information brochure, indicating the motivation for and characteristics of the study, as well as all relevant instructions. Employees were also informed that the study was conducted with the approval and support of the department's top management.

The following are the particulars of the questionnaire:

The questionnaire was developed on the basis of a thorough literature study of the theory and practice of human resource transformation and affirmative action. It contains 70 items and is divided into three sections. These are: Section $A$ :biographical information (occupational category, race, gender, age and length of employment), Section B: evaluation of perceptions relating to the transformation process, and Section C: evaluation of perceptions relating to the affirmative action process. The information gathered in sections $\mathrm{B}$ and $\mathrm{C}$, can be described as follows:

Section B: Evaluation of the transformation process:

Items 6-11: respondents' perceptions relating to the transformation strategy and process in the department. 
Items 12-17: respondents' perceptions relating to the management style of the department.

Items 18-21: these questions focus primarily on management staff and test respondents' knowledge of strategic management.

Section $\mathrm{C}$ : Evaluation of the affirmative action process:

Items 22-32: respondents' perceptions relating to affirmative action in the department.

Item 33: respondents' opinions relating to whether the affirmative action process in the department can be judged successful or not.

Items 34-43: respondents' opinions relating to factors that possibly relate to the failure of the affirmative action process.

Items 44-52: respondents' indications of factors that should form part of an affirmative action process.

Items 53-64: respondents' perceptions of the results of affirmative action after it was implemented in the department.

Items 65-70: respondents' indications to what extent they themselves are creating opportunities for advancement in the department.

The Likert-scale is used for the evaluation of the items in the following manner:

1 - completely

2 - to a larger extent

3 - to an extent

4 - to a lesser extent

5 - not at all

The reliability of the questionnaire was determined from the data obtained in this study. The Spearman-Brown split-half method was used, yielding a reliability coefficient of 0.72 .

\section{Research Group}

The research group consists of employees of a national, prominent public sector department. 


\section{Sample}

A random sample of 800 employees from a total employee population of 12391 was utilised.

\section{Response Rate}

With an expected response rate of about 50 per cent, 800 questionnaires were distributed, of which 355 were returned, indicating a response rate of 44.38 per cent.

\section{Data Analysis}

After the questionnaires were completed by the respondents, the data were captured in order to obtain statistical information for analysis and interpretation. The data derived from the questionnaires were analysed by means of descriptive and inferential statistics of the SPSS-Windows computer programme. The five biographical variables are presented in frequency tables below. The arithmetic means and standard deviations of the various elements and items of the questionnaire were used to determine significant tendencies, if any. The Oneway Analysis of Variance technique was used to determine the statistical significance of differences between two or more groups on one variable.

\section{Results of the Study}

Description of the sample: The five biographical variables are shown in the following five frequency tables:

Table 1 Broad occupational categories in the department

\begin{tabular}{|l|c|c|c|}
\hline \multicolumn{1}{|c|}{ Occupation } & Frequency & Per cent & $\begin{array}{c}\text { Cumulative } \\
\text { percentage }\end{array}$ \\
\hline Judiciary & 137 & 38.6 & 38.6 \\
\hline $\begin{array}{l}\text { Human resource } \\
\text { management }\end{array}$ & 143 & 40.3 & 78.9 \\
\hline Support staff & 27 & 7.6 & 86.5 \\
\hline Corporative services & 48 & 13.5 & 100 \\
\hline Total & 355 & 100 & \\
\hline
\end{tabular}

Table 1 indicates that most respondents belong to the human resource management occupational category, followed by judiciary, corporate services and support staff. 
Table 2 Race distribution

\begin{tabular}{|l|c|c|c|}
\hline Race & Frequency & Per cent & $\begin{array}{c}\text { Cumulative } \\
\text { percentage }\end{array}$ \\
\hline Asian & 25 & 7.0 & 7.0 \\
\hline Coloured & 41 & 11.5 & 18.6 \\
\hline Black & 104 & 29.3 & 47.9 \\
\hline White & 185 & 52.1 & 100.0 \\
\hline Total & 355 & 100 & \\
\hline
\end{tabular}

According to Table 2, White employees form the majority of the sample, followed by Black, Coloured and Asian employees.

\section{Table 3 Gender}

\begin{tabular}{|l|c|c|c|}
\hline Gender & Frequency & Per cent & $\begin{array}{c}\text { Cumulative } \\
\text { percentage }\end{array}$ \\
\hline Male & 176 & 49.6 & 49.6 \\
\hline Female & 179 & 50.4 & 100.0 \\
\hline Total & 355 & 100 & \\
\hline
\end{tabular}

Table 3 shows that male and female employees are almost equally represented in the sample, with female employees slightly in the majority.

\section{Table 4 Age distribution}

\begin{tabular}{|c|c|c|c|}
\hline Age & Frequency & Per cent & $\begin{array}{c}\text { Cumulative } \\
\text { percentage }\end{array}$ \\
\hline $\mathbf{1 8 - \mathbf { 2 5 }}$ & 57 & 16.1 & 16.1 \\
\hline $\mathbf{2 6} \mathbf{- 3 0}$ & 77 & 21.8 & 37.9 \\
\hline $\mathbf{3 1 - \mathbf { 4 0 }}$ & 129 & 36.4 & 74.3 \\
\hline $\mathbf{4 1 +}$ & 92 & 25.9 & 100.0 \\
\hline Total & 355 & 100 & \\
\hline
\end{tabular}

Table 4 indicates that the majority of employees in the sample are in the age group 31 to 40 years, followed by those in the age groups $41+, 26$ to 30 and 18 to 25 years. 
Table 5 Length of employment

\begin{tabular}{|l|c|c|c|}
\hline No. of years & Frequency & Per cent & $\begin{array}{c}\text { Cumulative } \\
\text { percentage }\end{array}$ \\
\hline 0 - 5 years & 131 & 36.9 & 36.9 \\
\hline 6 - 14 years & 131 & 36.9 & 73.8 \\
\hline 15 - 24 years & 62 & 17.5 & 91.3 \\
\hline 25 years + & 31 & 8.7 & 100.0 \\
\hline Total & 355 & 100 & \\
\hline
\end{tabular}

According to Table 5, employees in the groups 0-5 and 6-14 years of service form the majority in the sample, followed by employees with 15-24 and 25+ years of service.

The questionnaire: The results of the questionnaire items (sections B and C) are shown in Table 6.

Table 6 Descriptive statistics of the questionnaire

\begin{tabular}{|c|c|c|c|c|}
\hline $\begin{array}{c}\text { Item } \\
\text { number }\end{array}$ & Arith. Mean & $\begin{array}{c}\text { Std. } \\
\text { Deviation }\end{array}$ & Std. error & $\begin{array}{c}\text { Variance } \\
\text { width }\end{array}$ \\
\hline 6 & 2.685 & 1.110 & 0.059 & 1.234 \\
\hline 7 & 2.921 & 1.122 & 0.060 & 1.259 \\
\hline 8 & 2.701 & 1.162 & 0.062 & 1.351 \\
\hline 9 & 2.318 & 1.151 & 0.061 & 1.325 \\
\hline 10 & 2.451 & 1.039 & 0.055 & 1.079 \\
\hline 11 & 2.096 & 1.141 & 0.061 & 1.302 \\
\hline 12 & 2.777 & 1.225 & 0.065 & 1.502 \\
\hline 13 & 2.746 & 1.252 & 0.066 & 1.568 \\
\hline 14 & 3.237 & 1.233 & 0.065 & 1.520 \\
\hline 15 & 2.980 & 1.165 & 0.062 & 1.358 \\
\hline 16 & 3.101 & 1.135 & 0.060 & 1.289 \\
\hline 17 & 3.242 & 1.173 & 0.062 & 1.376 \\
\hline 18 & 0.344 & 0.806 & 0.043 & 0.650 \\
\hline 19 & 0.580 & 1.258 & 0.067 & 1.583 \\
\hline 20 & 0.600 & 1.275 & 0.068 & 1.625 \\
\hline 21 & 0.569 & 1.261 & 0.067 & 1.591 \\
\hline 22 & 2.346 & 1.330 & 0.071 & 1.769 \\
\hline 23 & 2.741 & 1.440 & 0.076 & 2.074 \\
\hline 24 & 2.637 & 1.428 & 0.076 & 2.040 \\
\hline 25 & 1.963 & 1.074 & 0.057 & 1.154 \\
\hline 26 & 2.946 & 1.221 & 0.065 & 1.491 \\
\hline & & & & \\
\hline
\end{tabular}


Table 6 continued

\begin{tabular}{|c|c|c|c|c|}
\hline $\begin{array}{c}\text { Item } \\
\text { number }\end{array}$ & Arith. Mean & $\begin{array}{c}\text { Std. } \\
\text { Deviation }\end{array}$ & Std. error & $\begin{array}{l}\text { Variance } \\
\text { width }\end{array}$ \\
\hline 27 & 3.079 & 1.183 & 0.063 & 1.401 \\
\hline 28 & 1.972 & 1.171 & 0.062 & 1.372 \\
\hline 29 & 2.220 & 1.218 & 0.065 & 1.483 \\
\hline 30 & 2.746 & 1.433 & 0.076 & 2.054 \\
\hline 31 & 2.659 & 1.327 & 0.070 & 1.762 \\
\hline 32 & 3.504 & 1.389 & 0.074 & 1.929 \\
\hline 33 & 1.561 & 0.623 & 0.033 & 0.388 \\
\hline 34 & 2.915 & 1.369 & 0.073 & 1.874 \\
\hline 35 & 3.082 & 1.300 & 0.069 & 1.691 \\
\hline 36 & 2.735 & 1.286 & 0.068 & 1.653 \\
\hline 37 & 2.831 & 1.313 & 0.070 & 1.723 \\
\hline 38 & 2.769 & 1.292 & 0.069 & 1.670 \\
\hline 39 & 2.727 & 1.366 & 0.072 & 1.866 \\
\hline 40 & 2.493 & 1.268 & 0.067 & 1.607 \\
\hline 41 & 2.721 & 1.234 & 0.066 & 1.524 \\
\hline 42 & 2.724 & 1.236 & 0.066 & 1.528 \\
\hline 43 & 2.538 & 1.184 & 0.063 & 1.402 \\
\hline 44 & 1.713 & 0.967 & 0.051 & 0.934 \\
\hline 45 & 1.676 & 0.935 & 0.050 & 0.875 \\
\hline 46 & 1.679 & 1.054 & 0.056 & 1.111 \\
\hline 47 & 2.828 & 1.366 & 0.072 & 1.866 \\
\hline 48 & 2.231 & 1.206 & 0.064 & 1.455 \\
\hline 49 & 2.490 & 1.187 & 0.063 & 1.409 \\
\hline 50 & 2.349 & 1.217 & 0.065 & 1.482 \\
\hline 51 & 1.887 & 1.068 & 0.057 & 1.140 \\
\hline 52 & 1.742 & 1.085 & 0.058 & 1.178 \\
\hline 53 & 2.901 & 1.139 & 0.060 & 1.298 \\
\hline 54 & 3.217 & 1.184 & 0.063 & 1.402 \\
\hline 55 & 2.690 & 1.221 & 0.065 & 1.491 \\
\hline 56 & 2.882 & 1.149 & 0.061 & 1.319 \\
\hline 57 & 3.158 & 1.136 & 0.060 & 1.291 \\
\hline 58 & 3.166 & 1.199 & 0.064 & 1.438 \\
\hline 59 & 2.794 & 1.214 & 0.064 & 1.475 \\
\hline 60 & 3.183 & 1.161 & 0.062 & 1.348 \\
\hline 61 & 3.155 & 1.047 & 0.057 & 1.154 \\
\hline 62 & 3.358 & 1.119 & 0.059 & 1.253 \\
\hline 63 & 3.389 & 1.135 & 0.060 & 1.289 \\
\hline 64 & 3.192 & 1.144 & 0.061 & 1.308 \\
\hline 65 & 2.473 & 1.215 & 0.064 & 1.476 \\
\hline
\end{tabular}


Table 6 continued

\begin{tabular}{|c|c|c|c|c|}
\hline $\begin{array}{c}\text { Item } \\
\text { number }\end{array}$ & Arith. Mean & $\begin{array}{c}\text { Std. } \\
\text { Deviation }\end{array}$ & Std. error & $\begin{array}{c}\text { Variance } \\
\text { width }\end{array}$ \\
\hline 66 & 1.775 & 0.977 & 0.052 & 0.955 \\
\hline 67 & 1.642 & 0.885 & 0.047 & 0.784 \\
\hline 68 & 1.921 & 1.223 & 0.065 & 1.479 \\
\hline 69 & 2.335 & 1.232 & 0.065 & 1.517 \\
\hline 70 & 2.986 & 1.411 & 0.075 & 1.991 \\
\hline
\end{tabular}

The following inferences can be drawn from Table 6:

Section B: Evaluation of the transformation process

Items 6-11: Average value of 3

Most respondents seem aware of the transformation strategy being followed and feel that they possess the necessary knowledge and experience to partake in the process.

Items 12-17: Average value of 3

Respondents seem to have a positive attitude towards the organisation culture and management style of the department.

\section{Items 18-21: Average value of 1}

The management staff of the department apparently indicate that they perceive strategic management as an important process in the public sector. They also seem to perceive the reaching of affirmative action objectives as part of the performance criteria for management.

Section C: Evaluation of the affirmative action process

Items 22-32: Average value of 2

Respondents seem to have reasonable knowledge of the affirmative action process in the public sector. They also seem to feel that the different cultures and values of employees should be taken into account to a certain extent, and that the public sector and the department apply affirmative action due to political and economic pressure. Item 32 shows an average value of 4 , seemingly indicating that respondents strongly feel that affirmative action should not carry more weight than merit.

\section{Item 33: Average value of 2}

Respondents seem to be of the opinion that affirmative action in the department is not being experienced as successful. 
Items 34-43: Average value of 3

Respondents seem to indicate that there are certain factors that do relate to the failure of the affirmative action process.

Items 44-52: Average value of 2

Respondents indicate that there are certain important factors that should be a part of a successful affirmative action process.

Items 53-64: Average value of 3

Respondents also indicate that there are certain important actions that their employer (the public sector) should execute more effectively.

Items 65-70: Average value of 2

Respondents evidently indicate that they are actively creating opportunities for advancement in the department for themselves.

One-Way Analysis of Variance: The results of this analysis are shown in tables 7 to 10 .

Table 7 One-way analysis of variance: Occupational category

\begin{tabular}{|l|c|c|}
\hline \multicolumn{1}{|c|}{ Variable } & F-value & P-value \\
\hline Perceptions of the transformation process & 3.6033 & $0.0000^{*}$ \\
\hline Perceptions of management style & 1.7043 & $0.371^{*}$ \\
\hline Knowledge of strategic management & 5.640 & $0.0000^{*}$ \\
\hline $\begin{array}{l}\text { Perceptions of the affirmative action } \\
\text { process }\end{array}$ & 1.7243 & $0.0339^{*}$ \\
\hline $\begin{array}{l}\text { Factors that should be part of the } \\
\text { affirmative action process }\end{array}$ & 1.7070 & $0.0366^{*}$ \\
\hline
\end{tabular}

$* \mathrm{P} \leq 0.05$

Table 7 indicates that occupational category has a significant effect on all five variables in the table

Post hoc comparison with the Scheffe test, however, showed the following :

No significant differences between the various occupational categories regarding perceptions of the transformation process.

No significant differences between the various occupational categories regarding management style.

No significant differences between the various occupational categories regarding perceptions of the affirmative action process. 
Table 8 One-way analysis of variance: Race

\begin{tabular}{|l|c|c|}
\hline \multicolumn{1}{|c|}{ Variable } & F-Value & P-Value \\
\hline Perceptions of the transformation process & 18.6324 & $0.0000^{*}$ \\
\hline Perceptions of management style & 20.7134 & $0.0000^{*}$ \\
\hline Knowledge of strategic management & 2.5862 & 0.0767 \\
\hline $\begin{array}{l}\text { Perceptions of the affirmative action } \\
\text { process }\end{array}$ & 10.0961 & $0.0001^{*}$ \\
\hline $\begin{array}{l}\text { Factors indicating a failure of the } \\
\text { affirmative action process }\end{array}$ & 3.3195 & $0.0373^{*}$ \\
\hline $\begin{array}{l}\text { Opinion relating to factors being part of a } \\
\text { successful affirmative action process }\end{array}$ & 1.7156 & 0.1814 \\
\hline $\begin{array}{l}\text { Factors reflected after implementation of } \\
\text { transformation \& affirmative action } \\
\text { processes }\end{array}$ & 11.8515 & $0.0000^{*}$ \\
\hline Advancement opportunities & 4.3005 & $0.143^{*}$ \\
\hline
\end{tabular}

$* \mathrm{P} \leq 0.05$

Table 8 indicates that race has a significant effect on the variables :

Perceptions of the transformation process.

Perceptions of management style.

Perceptions of the affirmative action process.

Factors indicating a failure of the affirmative action process.

Factors reflected after implementation of the transformation and affirmative action processes.

Advancement opportunities

Post Hoc comparison by means of the Scheffe test showed that White respondents differ significantly from Black respondents in terms of perceptions of the transformation process.

Table 9 One-way analysis of variance: Age

\begin{tabular}{|c|c|c|}
\hline Variable & F-value & P-value \\
\hline $\begin{array}{l}\text { Advancement } \\
\text { opportunities }\end{array}$ & 0.2706 & 0.7631 \\
\hline
\end{tabular}

$P \leq 0.05$

Table 9 indicates that the research group members' perceptions of advancement opportunities that they create for themselves in the department, do not have a significant effect on the various age groups. Post hoc comparisons with the Scheffe test also showed no significant differences between the age groups. 
Table 10 One-way analysis of variance: Length of employment

\begin{tabular}{|c|c|c|}
\hline Variable & F-value & P-value \\
\hline $\begin{array}{l}\text { Advancement } \\
\text { opportunities }\end{array}$ & 0.0581 & 0.9436 \\
\hline
\end{tabular}

$\mathrm{P} \leq 0.05$

Table 10 indicates that research group members' perceptions of advancement opportunities that they create for themselves in the department, do not have a significant effect on the various length of employment groupings. Post Hoc comparison with the Scheffe test also indicated no significant differences between the various groupings.

\section{CONCLUSIONS AND RECOMMENDATIONS}

Conclusions with regard to the questionnaire are the following:

Results from the questionnaire indicate that most of the respondents are aware of the fact that a formal transformation strategy and process operate in the department. They also feel that they do possess the necessary knowledge and experience to partake in the process. They do, however, indicate that they would like more information about the transformation process, and want to be timeously informed of all decisions being taken, all legal implications of the process, the exact nature of the process and how it is progressing. Respondents seem to feel reasonably positive about the organisation culture and leadership style of the department. Management staff indicated that they perceive strategic management as important within the transformational process, and are of the opinion that affirmative action objectives should also serve as performance evaluation criteria for management. Respondents seem to have reasonable knowledge of the affirmative action process in the department. They feel that the different cultural backgrounds and values of personnel should be considered in the process, and that the department and the public sector as a whole apply affirmative action because of political and economic pressures. Respondents strongly feel that affirmative action should not be more important than personal merit. Most respondents indicated that affirmative action in the department is not experienced as successful. They indicated that the following elements should be part of a successful affirmative action process :

High employee performance standards

Ability

Transparency

Qualifications and seniority

The determination of quotas 


\section{Equity}

The long term development of employees

Conclusions with regard to the One-Way Analysis of Variance are the following:

The independent variable "race" has a significant effect on the following dependent variables:

The transformation process

Management style

The affirmative action process

Failure of the affirmative action process

Factors that should be part of the affirmative action process Advancement opportunities

In terms of the variable perception of the transformation process, Black and White respondents showed significant differences. This tendency can possibly be attributed to White respondents' more negative feelings related to changes in departmental structures and processes.

In terms of the variable perception of the affirmative action process, White respondents differed significantly from Black, Coloured and Indian respondents. This might be attributed to the tendency that White respondents experience affirmative action as discriminatory, and feel that promotions is not based on merit.

In terms of the variable factors that could relate to the failure of the affirmative action process, White respondents differed significantly from Coloured and Indian respondents.

In terms of the variable factors reflected in the department after implementation of the transformation and affirmative action processes, White, Black, Indian and Coloured respondents differed significantly from one another.

In terms of the variable advancement opportunities, Black and White respondents differed significantly from one another. This can possibly be attributed to a tendency by Black respondents to feel that they are entitled to promotion because of past discrimination against them. White respondents seem to feel very unsure about their future career. No significant differences between the various age and length of employment groups were indicated in relation to this variable.

In terms of the variable knowledge of strategic management, the various race groups did not differ significantly from one another. 
The independent variable "occupational category" has a significant effect on the following dependent variables:

The transformation process.

Management style.

Strategic management.

The affirmative action process.

Factors that should be part of the affirmative action process.

In terms of the variables perceptions of the transformation process, perceptions of management style, as well as perceptions of the affirmative action process, no significant differences were indicated by the various occupational groups in the department.

With the experiences and results gained from the study, the following recommendations are suggested :

All organisations in South Africa should accept the fact that statutory intervention to enforce affirmative action, is a reality. Positive and successful affirmative action and employment equity, however, demand effective management.

Affirmative action should not be perceived to be executed in addition to other administrative tasks, but as an essential part of the organisation's strategic and operational objectives.

The implementation of affirmative action and employment equity depend on the organisation's culture and the critical role and functions of certain people.

The following specific recommendations for improving the affirmative action process in the department, are:

- The whole department should be included in the process. An affirmative action manager should be appointed, and line management should bear the responsibility for implementing the programme, not the human resource department.

- The organisation culture should change, so that affirmative action and employment equity, which include planning, structures, recruitment and selection, can be executed as part of total organisation strategy.

- Special training programmes should be presented to ensure that employees in certain designated groups acquire the necessary skills and qualifications.

- Quantifiable goals to be reached should be drawn up, as well as a timetable for reaching each goal. 
- Internal procedures or processes should be designed to monitor and evaluate the implementation of the affirmative action programme.

- The final responsibility for the affirmative action programme should rest with a senior manager in the department.

- All employees must receive regular feedback regarding the affirmative action process and all related issues.

\section{REFERENCES}

1 DE WAAL, J; CURRIE, L. \& ERASMUS, G. (1998) The Bill of Rights Handbook, Cape Town, Juta.

2 GERBER, P.P.; NEL, P.S. \& VAN DYK, P.S. (1998) Human Resources Management, $\left(3^{\text {rd }}\right.$ ed.), Goodwood, Southern Book Publishers.

3 LUHABE, W. (1993) "Affirmative Action: Creating the Reality", People Dynamics, 11(8).

4 SKRETNY, J.D. (1996) The Ironies of Affirmative Action: Politics, Culture and Justice in America, London, University of Chicago Press.

5 WINGROVE, T. (1995) Affirmative Action: A "How" Guide for Managers, Pretoria, Knowledge Resources.

6 WHITE PAPER ON AFFIRMATIVE ACTION IN THE PUBLIC SERVICE, Notice 564 of 1998, Government Printers, Pretoria.

7 WHITE PAPER ON HUMAN RESOURCES MANAGEMENT IN THE PUBLIC SERVICE, Notice 2011 of 1997, Government Printers, Pretoria.

8 WHITE PAPER ON THE TRANSFORMATION OF THE PUBLIC SERVICE, Notice 1227 of 1995, Government Printers, Pretoria. 